Hydrol. Earth Syst. Sci., 18, 1043-1052, 2014

www.hydrol-earth-syst-sci.net/18/1043/2014/

doi:10.5194/hess-18-1043-2014

(c) Author(s) 2014. CC Attribution 3.0 License.

\title{
Re-suspension of bed sediment in a small stream - results from two flushing experiments
}

\author{
A. Eder ${ }^{1,2}$, M. Exner-Kittridge ${ }^{1}$, P. Strauss ${ }^{2}$, and G. Blöschl ${ }^{1,3}$ \\ ${ }^{1}$ Centre for Water Resource Systems, Vienna University of Technology, Karlsplatz 13, 1040 Vienna, Austria \\ ${ }^{2}$ Federal Agency for Water Management, Institute for Land and Water Management Research, Pollnbergstraße 1, \\ 3252 Petzenkirchen, Austria \\ ${ }^{3}$ Institute of Hydraulic Engineering and Water Resources Management, Vienna University of Technology, \\ Karlsplatz 13/222, 1040 Vienna, Austria
}

Correspondence to: A. Eder (alexander.eder@baw.at)

Received: 26 August 2013 - Published in Hydrol. Earth Syst. Sci. Discuss.: 7 October 2013

Revised: 5 February 2014 - Accepted: 6 February 2014 - Published: 17 March 2014

\begin{abstract}
Streams draining small watersheds often exhibit multiple peaking sedigraphs associated with single peaking hydrographs. The process reasons of the multiple sediment peaks are not fully understood but they may be related to the activation of different sediment sources such as the stream bed itself, where deposited sediments from previous events may be available for resuspension. To understand resuspension of stream bed sediments at the reach scale we artificially flooded the small stream of the HOAL Petzenkirchen catchment in Austria by pumping sediment-free water into the stream. Two short floods were produced and flow, sediment and bromide concentrations were measured at three sites with high temporal resolution. Hydrologically, the two flood events were almost identical. The peak flows decreased from 57 to $7.9 \mathrm{~L} \mathrm{~s}^{-1}$ and the flow volumes decreased from 17 to $11.3 \mathrm{~m}^{2}$ along the $590 \mathrm{~m}$ reach of the stream. However, a considerably smaller sediment load was resuspended and transported during the second flood due to depletion of stream bed sediments. The exception was the middle section of the stream, where more sediment was transported during the second flood event which can be explained by differences between flow velocity and wave celerity and the resulting displacement of sediments within the stream. The results indicate that the first peak of the sedigraphs of natural events in this stream is indeed caused by the resuspension of stream bed sediments, accounting for up to six percent of the total sediment load depending on total flow volume.
\end{abstract}

\section{Introduction}

Understanding the sediment export from agricultural catchments is important for both land and water resources management. Erosion, land degradation and the transport of phosphorus are closely related to the sediment export (Kovacs et al., 2012). The occurrence of contaminants and particle-bound elements such as phosphorous in the stream can be related to the abundance of fine sediments (Mudroch and Azcue, 1995; Quinton et al., 2003). While it is difficult to measure erosion within a catchment in a representative way due to the enormous spatial variability in catchments (Walling, 1988; Prosser et al., 2001), monitoring the sediment concentrations in streams is a common way of indirectly measuring the bulk erosion from the catchment. However, in many environments sediment losses measured on the field scale are much higher than the sediment loads measured in the stream (e.g. Millington, 1981). This is because much of the sediment is deposited prior to reaching the stream or deposited in the stream network itself prior to reaching the catchment outlet (Merrit et al., 2003; De Rose et al., 2003).

There are many processes influencing the erosion, transport, deposition and remobilisation of sediments. Most of these factors vary significantly between events, even if the hydrograph shape is similar. There is seasonal variation due to vegetation dynamics and antecedent soil moisture, variation due to different runoff mechanisms (infiltration excess vs. saturation excess) and variation due to differences in the rainfall intensities and spatial rainfall patterns (Soler et 


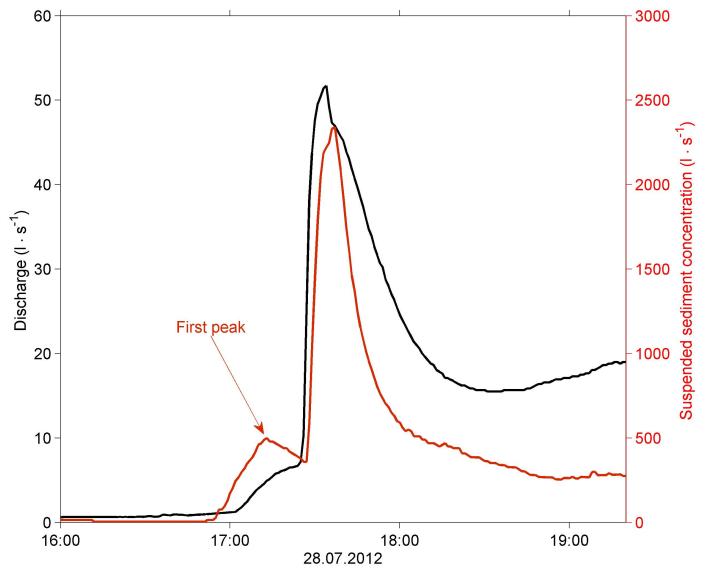

Fig. 1. Natural event with single peaking hydrograph and double peaking sedigraph in the HOAL Petzenkirchen catchment ( 0.64 ha) on 28 July 2012.

al., 2008; Lana-Renault and Regüés, 2009; Giménez et al., 2012). In large catchments not all of these process variations may be visible in the sedigraph because of long pathways and the averaging of component processes, so there tends to be a close correspondence between sedigraphs and hydrographs. However, in small catchments many scientists have observed massive differences between the timing and shape of the hydrographs and the sedigraphs. Often, there is a temporal shift, resulting in either clockwise or counter-clockwise hysteresis when plotting flow against sediment concentrations, and multiple peaking sedigraphs are often associated with single peaking hydrographs (Kronvang et al., 1997; Brasington and Richards, 2000; Petticrew et al., 2007; Eder et al., 2010; Yeshaneh et al. 2013). As an example, Fig. 1 shows a hydrograph and the associated sedigraph of the HOAL catchment in Petzenkirchen, where small sediment peaks often occur in advance of the main sediment and discharge peak. Seeger et al. (2004) observed similar early sediment peaks in a small headwater catchment in the Spanish Pyrenees.

Many authors relate these observations to the activation of different sediment sources such as the resuspension from stream bed sediments (Williams, 1989; Kronvang et al., 1997; Lenzi and Marchi, 2000; Eder et al., 2010). Although the movement of bed load for stream bed stability analyses is well investigated, the behaviour of fine sediments, often simplified as wash load, is less well investigated (Petticrew et al., 2007). However, it is the latter that reflects the amount of eroded sediments from the fields in agricultural catchments. Also, little information is available on the resuspension of fine sediments from the bed of small streams that were deposited during the tailing limb of the previous events and the transportation out of the catchment. Much of the difficulty in analysing these processes is related to the hydrological variability between events. Each and every event is different, which makes it very difficult to unravel the individual

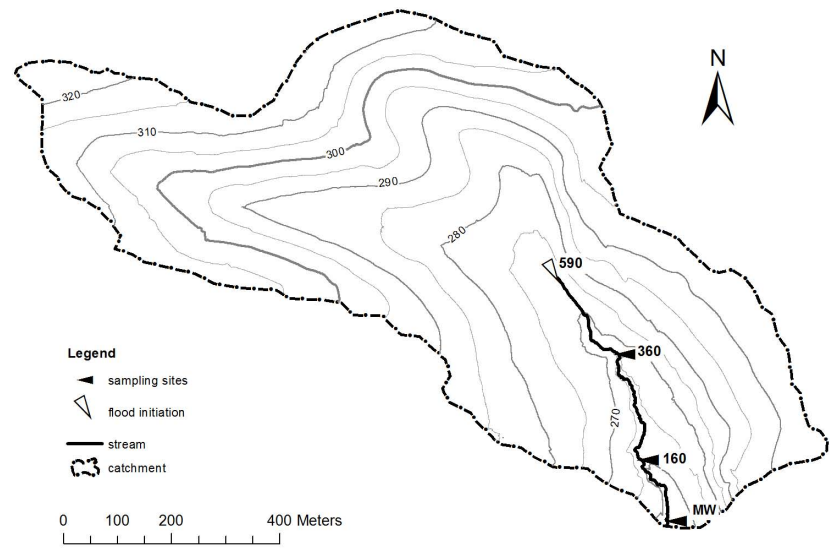

Fig. 2. HOAL catchment with point of flood initiation (590) and measurement sites $(360,160, \mathrm{MW})$.

factors driving the processes of sedimentation and resuspension. What is needed are repeatable experiments (Blöschl and Zehe, 2005).

This paper therefore reports on reach-scale experiments of controlled water inputs into a small stream to understand the resuspension, transport and deposition processes of fine sediments. Specifically, the following science questions are addressed for an experimental catchment: (i) what is the magnitude of re-suspension of fine sediments from the stream bed? (ii) What is the source of these re-suspended sediments (catchment erosion during previous events or the channel bank)? (iii) Is the early peak in the sedigraphs of natural events due to the re-suspension of sediment from the stream bed?

\section{Study site}

The flooding experiments were conducted in the Hydrological Open Air Laboratory (HOAL) Petzenkirchen (Fig. 2). It is situated in the western part of Lower Austria and has a size of 64 ha. It is jointly operated by the Federal Agency for Water Management and the Technical University of Vienna to study catchment processes from data with high temporal and spatial resolution. Climate in the catchment can be characterised as humid, with a mean annual temperature of $9.3{ }^{\circ} \mathrm{C}$ and a mean annual rainfall of $716 \mathrm{~mm}$. Temperature, rainfall and rainfall intensity have their peak during summertime. The elevation of the catchment ranges from 257 to $325 \mathrm{~m}$ above sea level. An overall $87 \%$ of the catchment area is arable land, $5 \%$ is used as pasture, $6 \%$ is forested and $2 \%$ is paved. The dominant soil types are Cambisols and Planosols (FAO et al., 1998) with medium to poor infiltration capacities and underlying geology of Quaternary sediments. Mean annual flow of the last decade was $3.8 \mathrm{~L} \mathrm{~s}^{-1}$ but flow drops in summertime to less than one litre per second. Maximum observed flow was around $2 \mathrm{~m}^{3} \mathrm{~s}^{-1}$ during a big flood in 2002. The 
stream itself has an open length of $590 \mathrm{~m}$ with a medium slope of $2.4 \%$ (Fig. 3). Additionally, the uppermost $25 \%$ of the stream length were piped in the 1950 s to enlarge the agricultural production area. The piped section of the stream is not included in the length of $590 \mathrm{~m}$. The deposited material on the stream bed mainly consists of silt $(68 \%)$, followed by clay $(18 \%)$ and sand $(14 \%)$.

In the upstream section of the stream, bank slope ratio is almost $1: 1$. The stream is very narrow (Fig. 4, left) and a change in flow leads to a significant change in the water level. In the area of the catchment outlet, the stream reaches a width of approximately one metre (Fig. 4, right). The banks are very shallow and are flooded during medium-sized floods. After the small river bed is flooded it takes a substantial increase in flow to produce a significant increase in water level. The longitudinal section of the stream (Fig. 3) shows a number of steps, followed by pools and sections with varying slopes.

Low gradient sections of the stream with small water velocities tend to be covered by deposited fine sediments, whereas in the steep sections the Quaternary material is visible. At the latter the quaternary underground is often coated with precipitated carbon and is resistent to erosion.

\section{Experimental setup}

Two flooding experiments were conducted in 2011 on 24 and 31 August, respectively. Prior to the experiments, three temporary water reservoirs were set up at the beginning of the open stream (site 590 in Fig. 1). They were filled with stream water one day before the flooding experiments. Bromide was added to the water as a tracer. The reservoirs were fitted with three pumps with a nominal flow rate of a total of $56.7 \mathrm{~L} \mathrm{~s}^{-1}$. The pumps were started with a delay of $1 \mathrm{~min}$ and pumped water into the stream directly at site 590. Due to different sizes of the pumps (two smaller and one bigger pump) and the delayed start of each pump, a stepwise initial flood was produced. The flow from the hoses was stabilised in a wooden box to minimise the stir-up of sediments from the stream bed. The total capacity of the reservoirs was $24 \mathrm{~m}^{3}$ but it was not possible to empty the water reservoirs completely, so the actual water volume pumped into the stream was $16.9 \mathrm{~m}^{3}$ at the first flood and $17.1 \mathrm{~m}^{3}$ at the second flood.

Flow in the stream at site 590 was measured by a calibrated H-Flume fitted with a pressure transducer where water levels were logged at $1 \mathrm{~min}$ intervals. For the flow measurements at site 360 and site 160 , V-notch weirs were installed in the stream bed. At both sites we recorded water level, turbidity, conductivity and temperature at $1 \mathrm{~min}$ intervals and took manual water samples at $2 \mathrm{~min}$ intervals for the first $40 \mathrm{~min}$ after the first increase of the water level. Additionally, automated samplers were installed at these sites with a sampling interval of $20 \mathrm{~min}$ to capture the tail of the flood waves. We did not use the automated samplers directly after the first in-

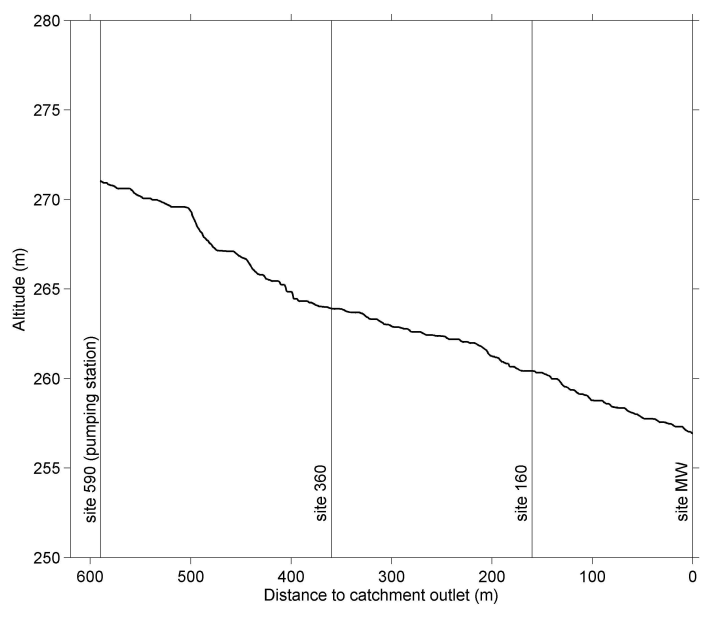

Fig. 3. Longitudinal section of the stream in the HOAL catchment with measurement sites.

crease of the water level, because the minimum sampling interval of 5 min attainable with the sampler was considered to be too long for the flow dynamics of interest. The water samples were analysed for suspended sediment concentration and bromide concentration in the laboratory. Final sediment concentrations were calculated from the readings of the turbidity probes which were calibrated with manual and automated sampler data for each single site separately.

At the catchment outlet (site MW) we measured flow with an $\mathrm{H}$-flume and a pressure transducer, at 1 min intervals. Turbidity, electrical conductivity and water temperatures were also measured at $1 \mathrm{~min}$ intervals. Additionally we took water samples using the same procedures as for sites 360 and 160 .

The weather and the hydraulic conditions in the stream prior to the flooding events were almost identical. Although there was some rain and discharge began to rise a few days in advance of both flooding experiments, directly before the tests, base flow conditions were reached again (Fig. 5). It is assumed that only a negligible part of sediment was transported at the natural rainfall event between the flooding tests, because turbidity did not show a clear response to the increased flow rate.

\section{Results}

The hydrographs of the two flooding experiments are shown in Fig. 6. For the first experiment (Fig. 6a) the maximum flow rate measured at the pumping station (site 590) was $57 \mathrm{~L} \mathrm{~s}^{-1}$ which is close to the nominal capacity of the pumps. There is a strong dispersion of the flood wave and thus a significant reduction of the maximum flow rate along the stream from $57 \mathrm{~L} \mathrm{~s}^{-1}$ at site 590 to $21.5,10.0$ and $8.7 \mathrm{~L} \mathrm{~s}^{-1}$ at sites 360, 160 and the catchment outlet, respectively. The total volume of water pumped into the stream was $16.9 \mathrm{~m}^{3}$ and decreased to $15.2,13.3$ and $11.3 \mathrm{~m}^{3}$ at sites 360,160 and 


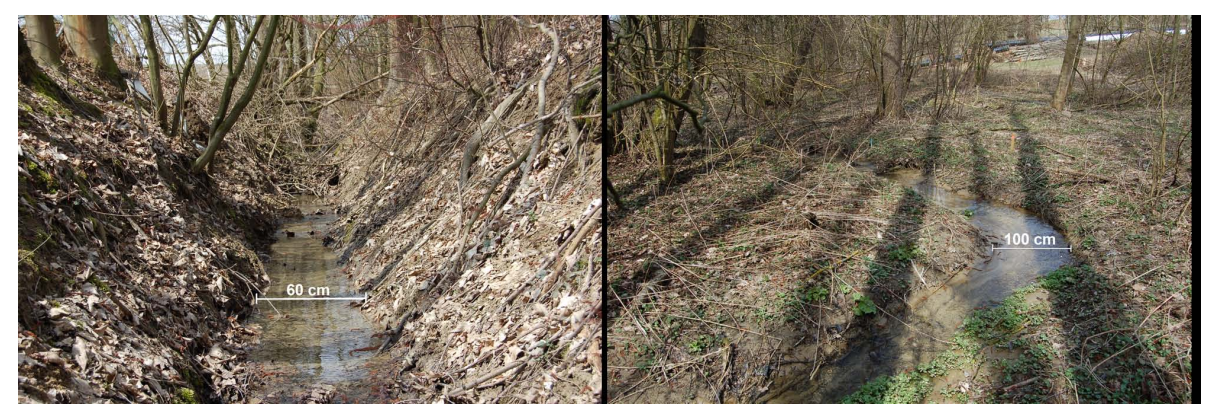

Fig. 4. Upstream section of the stream in the HOAL catchment close to the pumping station (left panel) and downstream section close to the catchment outlet (right panel). Width of stream is indicated in the photos for comparison. Both photos are upstream views.

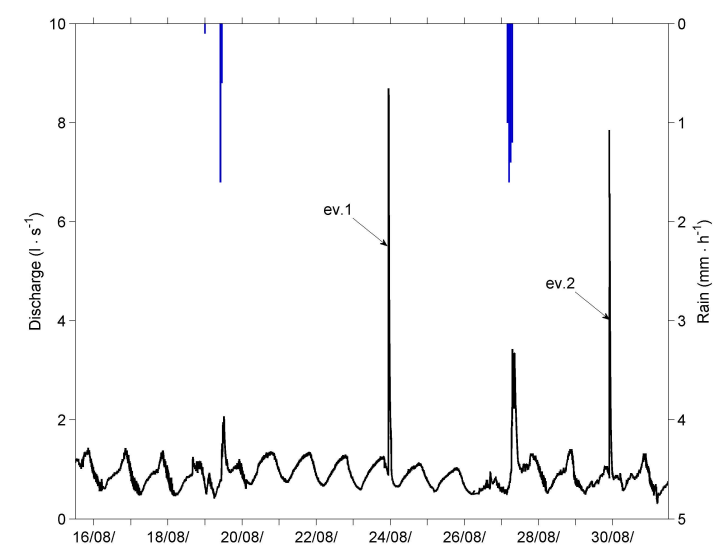

Fig. 5. Hyetograph and discharge at the catchment outlet (site MW) 10 days before and during the flooding events in August 2011.

the catchment outlet, respectively. The reduction in volume along the stream (Fig. 8) is due to transient storage, i.e. storage in either stream channel dead zones (side pools, eddies) or exchanges through the hyporheic zone (Gooseff et al., 2007).

The hydrographs of the second experiment (Fig. 6b) are almost identical to the hydrographs of the first experiment. The maximum flow rates decreases from $57 \mathrm{~L} \mathrm{~s}^{-1}$ at the pumps to $20.7,9.9$ and $7.9 \mathrm{~L} \mathrm{~s}^{-1}$ at the downstream sites. The measured water volumes decreased from $17.1 \mathrm{~m}^{3}$ to 14.7 , 12.9 and $11.7 \mathrm{~m}^{3}$. The close similarity of the hydrograph characteristics is important, as the flooding experiments were designed as repeated experiments to infer the differences in sediment characteristics for flood waves that are otherwise similar.

To shed light on the sources of the transported sediments Fig. 9 compares the time lags of the hydrograph dynamics representing wave celerities (Fig. 9a), the time lags of the sediment (Fig. 9b) and the time lags of the bromide tracer representing flow velocities (Fig. 9c). The first rise of the hydrograph at site 360 occurred $18 \mathrm{~min}$ after starting the pumps. It took $32 \mathrm{~min}$ to see the first rise at site 160 and $54 \mathrm{~min}$ at the MW (Fig. 9a). Since the hydrographs of the two experi- ments are almost identical, the time lags for the second event are very similar (17, 32 and $52 \mathrm{~min}$ ). The first appearance of sediments is simultaneous with the first rise of the hydrograph. In the first experiment the sediment concentrations at the individual sites along the stream increased 18, 33 and 55 min after starting the pumps (Fig. 9b). In the second experiment they increased 17, 34 and 53 min after starting the pumps. In the first experiment the first detection of bromide occurred 20, 38 and $86 \mathrm{~min}$ after starting the pumps, and in the second experiment after 20,41 and $75 \mathrm{~min}$ at sites 360 , 160 and MW, respectively. This means that first detection of bromide occurred later than the rise of the hydrograph.

\section{Discussion}

\subsection{Source and magnitude of re-suspended sediments}

The most striking feature of the two experiments is that the hydrographs are almost identical. Indeed the experiments were designed in a way to make the two flooding events identical replicas from the perspective of water flow. In the two flooding experiments approximately equal flow maxima were measured at the individual stations along the stream. Also, the decrease of the total runoff volume is almost identical. In both experiments, apparently, exfiltration into the groundwater and surface ponding occurred, as would be expected for this type of events (Wondzell et al., 2010). As shown in Fig. 5, there was no impact of rainfall on the base flow conditions between the two experiments, so we can safely assume that the hydrological conditions (including soil moisture and groundwater tables) were very similar. This similarity allows a comparison of sediment processes purely based on the availability of sediments in the stream. With the experimental setup it was ensured that no sediment was delivered from the fields. Therefore, the only sediment sources were the stream bed itself, stream banks or deposited sediments of previous events. Due to the fact that the stream bed is cut into the molassic subsurface and has been stable for several decades, a further deepening and thus direct erosion of the stream bed can be excluded. Bank erosion, on the 

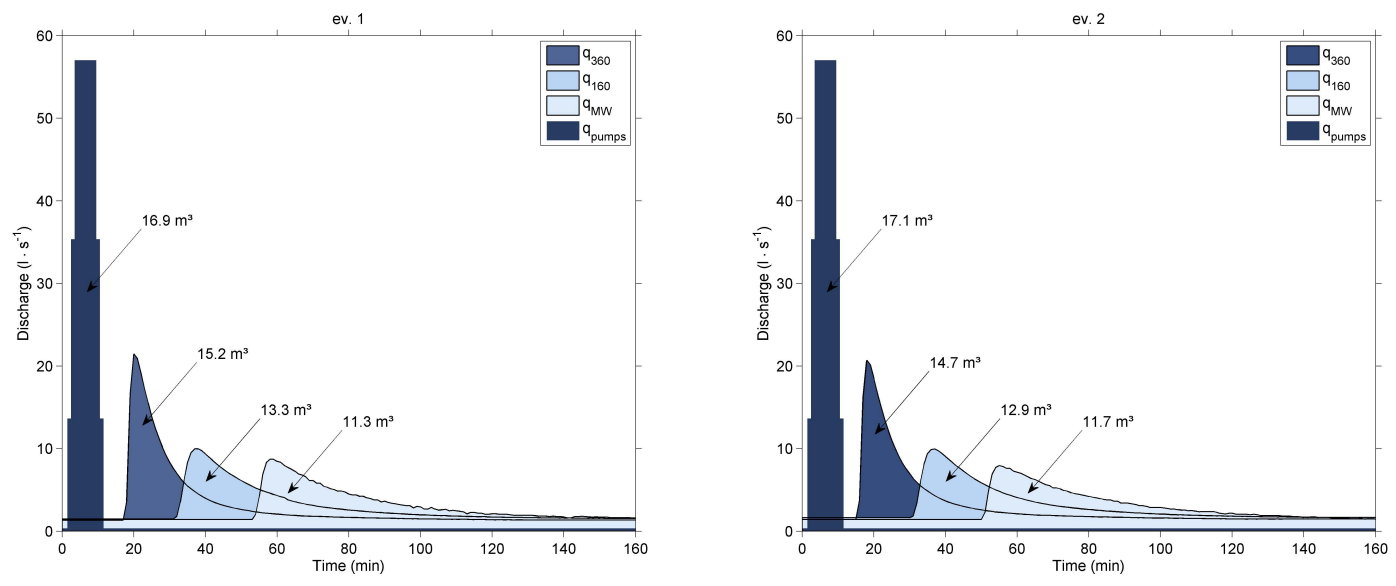

Fig. 6. Hydrographs of the first (ev.1) and second (ev.2) flooding experiment at the flood initiation location and three monitoring sites (see Fig. 2).
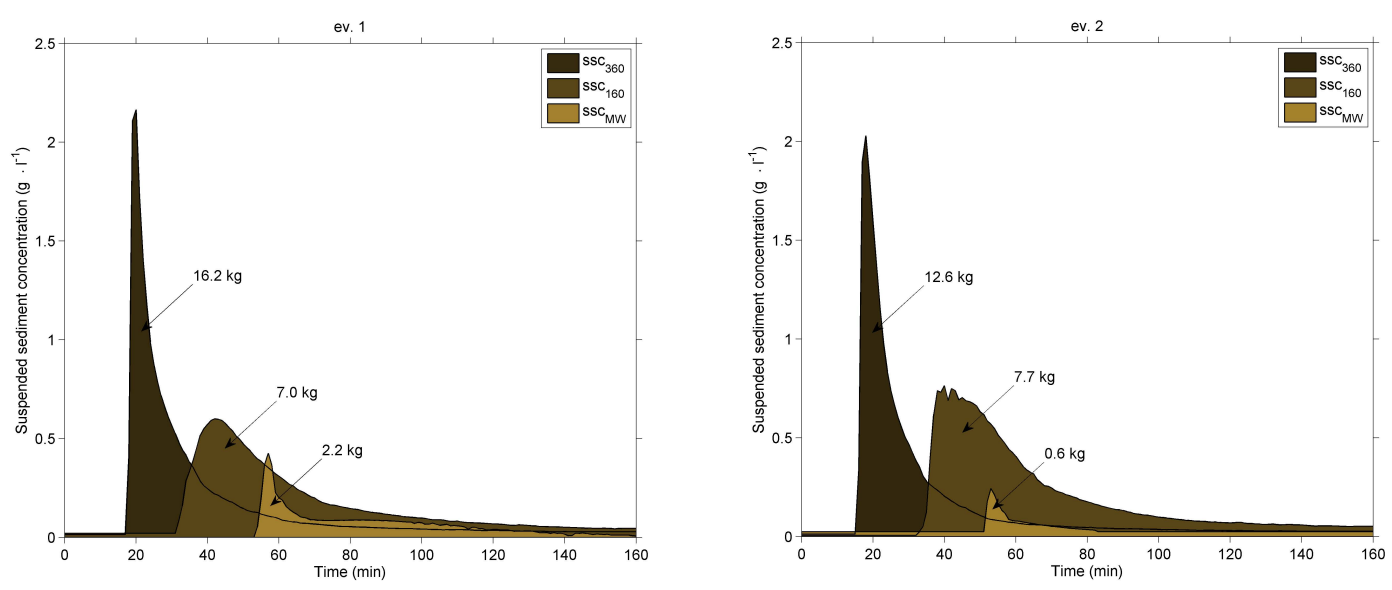

Fig. 7. Sedigraphs of the first (ev.1) and second (ev.2) flooding experiments at the three monitoring locations (see Fig. 2).

other hand, is a local phenomenon and can never be excluded. However, the immediate increase in sediment concentration at the onset of the hydrograph suggests that the main source of the sediments is resuspension of previously deposited sediments, either from the stream bed or from the flood plains. This is also supported by the finding that significantly less sediment was transported during the second flooding experiment, although hydraulic conditions were identical. Thus, the sediment deposits on the stream bed were depleted during the first experiment.

The estimated hydraulic conditions at maximum discharge at the measurement sites indicate transport of sediments with a maximum diameter of $45 \mathrm{~mm}$ at the upper section, declining to $9 \mathrm{~mm}$ at the middle section where minimum shear stress occurred due to lowest topographic gradient (Table 2). For the estimations' mean section slope, mean section velocities and characteristic stream widths were applied and the Shields parameter was assumed to be 0.05 . Using a simple Kresser equation (Kresser, 1964) for fine silt $(0.002$ to $0.006 \mathrm{~mm}$ ) the critical velocity for suspension is $0.15 \mathrm{~m} \mathrm{~s}^{-1}$ which was exceeded at maximum discharge at the upper and the middle section. This means a transport in suspended form of both fine silt and silt at these sections during high flow conditions. Only at the downstream section was velocity always lower than the critical value. The maximum diameter of suspended sediment was $0.004 \mathrm{~mm}$ for the given transport velocity of $0.12 \mathrm{~m} \mathrm{~s}^{-1}$.

The sediment load transported by the stream at the various sections decreased along the stream (Fig. 7). This is consistent with the decreasing discharge and flow velocities according to transport capacity concepts (e.g. Merrit et al., 2003). As noted above, the sedigraphs of the two flooding experiments differed although the hydraulic conditions were identical. At site 360 the sediment load of the second experiment was $22 \%$ smaller than that of the first experiment. At the catchment outlet the sediment load of the second experiment was even $72 \%$ smaller than that of the first experiment.

However, contrary to our initial expectations, at the middle section (site 160) the sediment load of the second experiment increased by $10 \%$ relative to the first experiment. Possible 
Table 1. Wave celerities estimated from the hydrograph dynamics, velocities of sediment transport estimated from the sedigraphs and flow velocities estimated from the bromide tracer samples. All estimates are for the first appearance (first rise) of the signal as in Fig. 9.

\begin{tabular}{|c|c|c|c|c|c|c|c|}
\hline & \multirow[b]{2}{*}{$\begin{array}{c}\text { Mean } \\
\text { topographic } \\
\text { gradient } \\
\left(10^{-3}\right)\end{array}$} & \multicolumn{3}{|c|}{ Event 1} & \multicolumn{3}{|c|}{ Event 2} \\
\hline & & 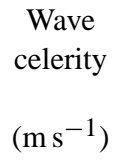 & $\begin{array}{c}\text { Sediment } \\
\text { velocity } \\
\left(\mathrm{m} \mathrm{s}^{-1}\right)\end{array}$ & $\begin{array}{c}\text { Flow velocity } \\
\text { from bromide } \\
\text { tracer } \\
\left(\mathrm{m} \mathrm{s}^{-1}\right)\end{array}$ & 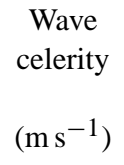 & $\begin{array}{c}\text { Sediment } \\
\text { velocity } \\
\left(\mathrm{m} \mathrm{s}^{-1}\right)\end{array}$ & $\begin{array}{l}\text { Flow velocity } \\
\text { from bromide } \\
\text { tracer } \\
\quad\left(\mathrm{m} \mathrm{s}^{-1}\right)\end{array}$ \\
\hline $\begin{array}{l}\text { Site } 590 \\
\text { to } 360\end{array}$ & 31 & 0.213 & 0.213 & 0.192 & 0.225 & 0.225 & 0.192 \\
\hline $\begin{array}{l}\text { Site } 360 \\
\text { to } 160\end{array}$ & 17 & 0.238 & 0.222 & 0.185 & 0.222 & 0.196 & 0.159 \\
\hline $\begin{array}{l}\text { Site } 160 \\
\text { to MW }\end{array}$ & 22 & 0.121 & 0.116 & 0.056 & 0.133 & 0.140 & 0.078 \\
\hline
\end{tabular}
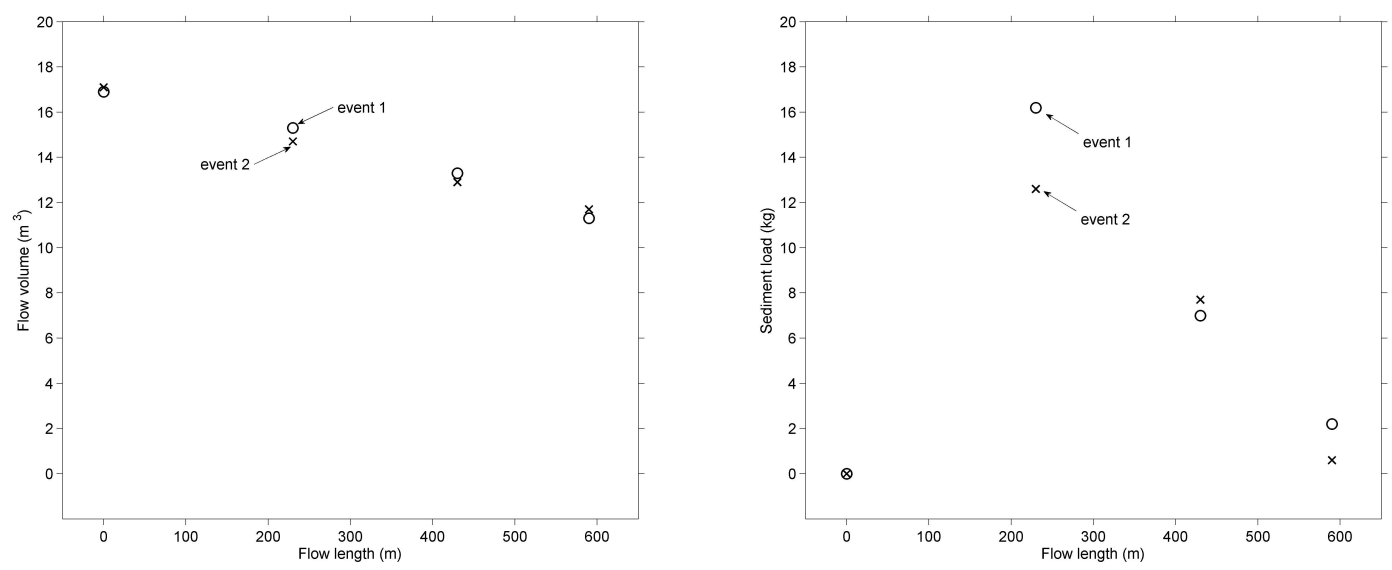

Fig. 8. Comparison of water volumes and sediment loads transported along the stream for the two flooding experiments (event 1 and event 2 ). Water flow is from left to right.

reasons for this increase are a bank collapse upstream of the site and/or a change in the availability of sediments along the stream. The latter is supported by the bromide tracer results. The ratio between wave celerity and bromide velocity is approximately one at the upper section and increases to 2.2 near the catchment outlet (Table 1), indicating that transport velocity is lower than wave celerity in the downstream section. Due to the immediate rise of sediment concentrations when flow starts to increase, the sediments must originate from the stream bed directly upstream of the measurement site. Because of the short duration of the flood wave and the differences between celerities and velocities, the sediments are likely transported for only a limited length and then re-deposited as the transport capacities decrease when the wave recedes after its maximum. This interpretation of limited transport length is supported by travel distance studies within flumes from Parsons and Stromberg (1998) and Bryan and Brun (1999). These results, along with the data from this study, suggest that a considerable amount of fine sediment was transported during the first flooding experiment to site 160 . These sediments were then easily available for the second flooding. Because of the higher ratio between celerity and velocity and lower flow rates downstream, less sediment was transported in this section. The sediment delivery from the upper part of the reach is limited. Furthermore, the stream has a complex geometry, with small steps followed by pools which may act as temporary sediment sinks. One would expect that the influence of these pools is related to the mean exchange rate with the main stream and therefore depends on the discharge. This process reasoning suggests that the higher sediment loads at site 160 in the second experiment (relative to the first) are real and can be explained by the differences in sediment availability along the stream. However, the main pattern is that the sediments on the stream bed were depleted during the first experiment, leading to smaller sediment loads at the catchment outlet in the second experiment.

\subsection{Comparison with natural events}

A crucial point of the study was the comparison of the resuspension experiments with the first flush sediment load of 

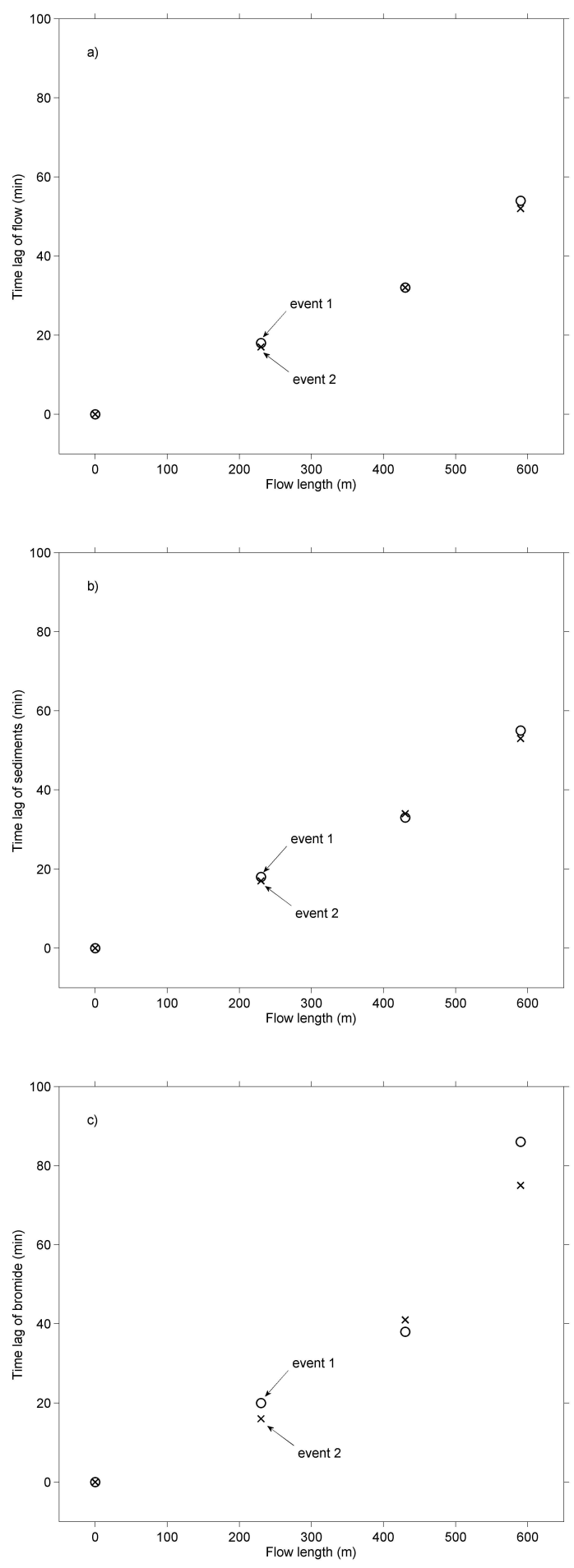

Fig. 9. Time lag of water (celerity) (a), sediment (b) and bromide (velocity) (c) for the two flooding experiments (event 1 and event 2) estimated from the first appearance (first rise) of the signal.

natural events. The results of the experiment suggest that the first flush sediment peak of a natural rainfall-runoff events in the catchment are indeed caused by resuspension. Especially for short duration storms with high rainfall intensities, the time for transporting eroded sediments from the fields to the catchment outlet is not long enough to take these sediments out of the catchment. In our experiments, the main part of the event was around $20 \mathrm{~min}$, while it took the water around 80 min to reach the catchment outlet. Most of the sediment must therefore remain somewhere on the pathway.

It is now of interest to compare the flooding experiments with natural events. Data of natural events from the years 2006 and 2007, taken from Eder et al. (2010), were used for the comparison. Relationships between sediment concentrations and discharge for both the flooding experiments and the natural events are plotted in Fig. 10. On average, the relationships for the flooding experiments (Fig. 10a) and the natural events from the years 2006 and 2007 (Fig. 10b) are very similar. This suggests that enough sediment is available for resuspension in the natural events. However, the relationships of the two experiments are much more consistent than those of the individual natural events because of the similarity in the hydrological conditions.

For evaluating the resuspension during natural events, six events were selected where a clear first flush peak could be identified. These were used to calculate the contribution of the first flush sediments to the total sediment load (Table 3). The results indicate that the proportion of first flush (resuspension) sediment load to the total load is between 0.1 and $6 \%$. For comparison, the corresponding values of the flooding experiments are reported. The sediment concentrations and loads of the experiments are listed under first peak as they stem from resuspension. The total export of the two experiments was 2.2 and $1.6 \mathrm{~kg}$, respectively, while the first flush export of the natural events usually ranged between 0.1 and $5.6 \mathrm{~kg}$ with the exception of the June 2007 event. A possible reason for the extraordinarily high sediment concentrations of the June 2007 event can be the planting of maize on the most sensitive fields for erosion in the catchment and the less developed plant stadium at that time of the year. Therefore, the soil was not covered and easily erodible.

As the event magnitude of the natural events increases, the relative contribution of the first flush relative to the total load decreases (Fig. 11). This would be expected as a result of the depletion of the sediment deposits on the stream bed during the events and the corresponding increase of total sediment load because of enlargement of sediment-contributing areas. The March 2007 event exhibits a large total flow volume $\left(584 \mathrm{~m}^{3}\right)$ but the lowest contribution of first flush peak to total sediment load. In contrast, the April 2006 event shows the lowest total flow volume $\left(88 \mathrm{~m}^{3}\right)$ but the highest relative first flush sediment load.

The contribution of the first flush sediment load is much smaller than the figures for bed/bank erosion reported in the literature. For example, Kronvang et al. (1997) reported a 
Table 2. Estimated hydraulic conditions at maximum discharge at the measurement sites and associated critical mean sediment diameter.

\begin{tabular}{|c|c|c|c|c|c|c|c|c|}
\hline & \multicolumn{4}{|c|}{ Event 1} & \multicolumn{4}{|c|}{ Event 2} \\
\hline & $\begin{array}{l}\text { Flow } \\
\text { depth } \\
(\mathrm{m})\end{array}$ & $\begin{array}{c}\text { Shear } \\
\text { velocity } \\
\left(\mathrm{m} \mathrm{s}^{-1}\right)\end{array}$ & $\begin{array}{c}\text { Shear } \\
\text { stress } \\
\left(\mathrm{Nm}^{-2}\right)\end{array}$ & $\begin{array}{c}\text { Mean } \\
\text { critical } \\
\text { diameter } \\
(\mathrm{mm})\end{array}$ & $\begin{array}{l}\text { Flow } \\
\text { depth } \\
\text { (m) }\end{array}$ & $\begin{array}{c}\text { Shear } \\
\text { velocity } \\
\left(\mathrm{m} \mathrm{s}^{-1}\right)\end{array}$ & $\begin{array}{c}\text { Shear } \\
\text { stress } \\
\left(\mathrm{N} \mathrm{m}^{-2}\right)\end{array}$ & $\begin{array}{c}\text { Mean } \\
\text { critical } \\
\text { diameter } \\
(\mathrm{mm})\end{array}$ \\
\hline Site 360 & 0.17 & 0.19 & 37 & 45 & 0.16 & 0.19 & 35 & 44 \\
\hline Site 160 & 0.05 & 0.09 & 8 & 10 & 0.05 & 0.09 & 8 & 10 \\
\hline Site MW & 0.07 & 0.12 & 14 & 17 & 0.07 & 0.11 & 13 & 16 \\
\hline
\end{tabular}
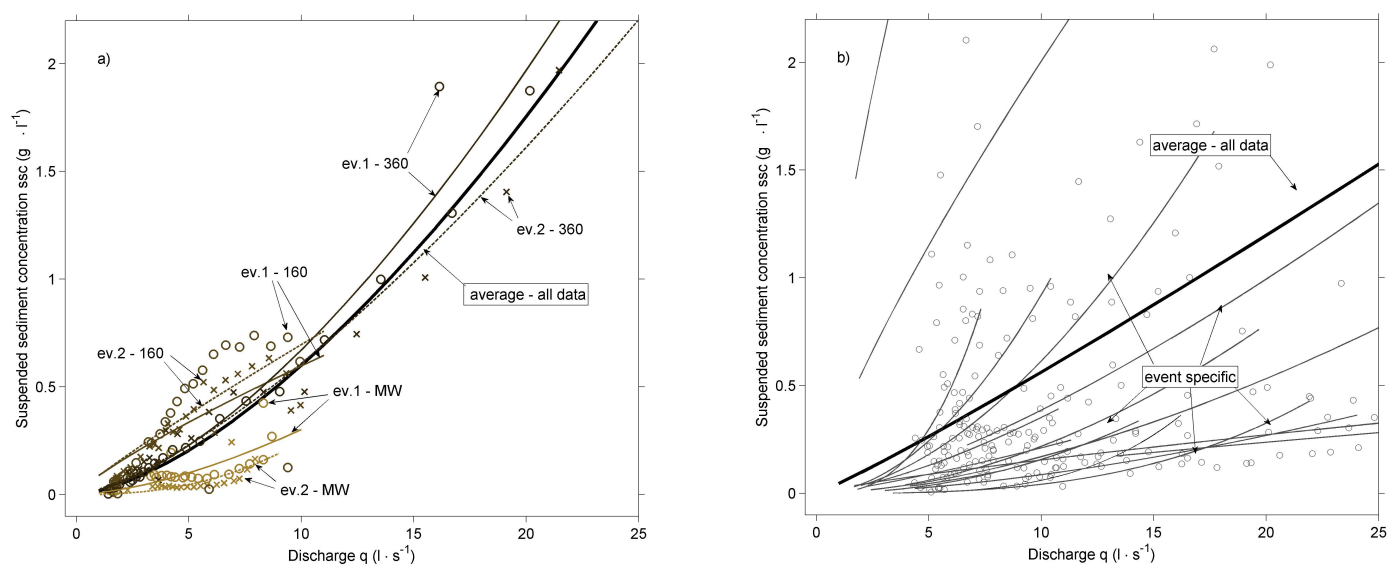

Fig. 10. Relationship between sediment concentrations and discharge of the flooding experiments (a) and natural events ((b), modified from Eder et al., 2010) in the HOAL catchment.

contribution of $66-89 \%$ for the lowland river in Denmark. Therefore, it is very likely that in the case of the HOAL catchment the first sediment peak is caused by resuspension, but resuspension also occurs later during the event. As long as sediments are available in the stream bed and the critical shear stress or transport capacity is high enough, resuspension will happen. Whether the sediment is exported from the catchment or just displaced within the reach depends on the event characteristics, in particular on the duration and magnitude of the event. The amount of resuspension is also affected by the deposition characteristics of the previous event, as demonstrated by the differences in the sedigraphs in this study. If a summer storm with high erosion rates (but short duration) transports a lot of sediment from the fields to the stream, much of the sediment will be available for the following event. In contrast, a long event with low intensities and low erosion rates may resuspend most of the stream bed sediment and not leave much sediment for the following event. Furthermore, the grain size distribution of the available and transported sediments will play an important role. For instance, Petticrew et al. (2007) reported that more mass but smaller grain sizes were transported during the falling limb of the hydrograph. This could lead to a big resource for easily available sediments when the ratio between flow celerity and velocity is high.

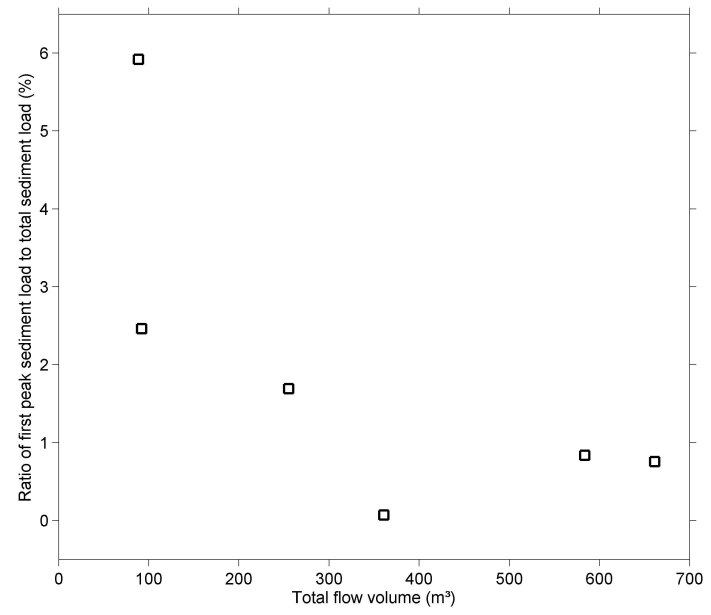

Fig. 11. Ratio of first flush sediment load to total sediment load of natural events as a function of total flow volume in the in the HOAL catchment (64 ha) (see Table 3). 
Table 3. Characteristics of natural events and the flooding experiments at the outlet of the HOAL catchment (64 ha). The sediment concentrations and loads of the experiments are listed under first peak as they stem from resuspension.

\begin{tabular}{|c|c|c|c|c|c|c|c|}
\hline & $\begin{array}{c}\text { Water volume } \\
\text { of event } \\
\mathrm{m}^{3}\end{array}$ & $\begin{array}{c}\text { Max. discharge } \\
\text { of event } \\
\mathrm{L} \mathrm{s}^{-1}\end{array}$ & $\begin{array}{c}\text { Max. sediment } \\
\text { concentration } \\
\text { of event } \\
\mathrm{mg} \mathrm{L}^{-1}\end{array}$ & $\begin{array}{l}\text { Max. sediment } \\
\text { concentration } \\
\text { of first peak } \\
\mathrm{mg} \mathrm{L}^{-1}\end{array}$ & $\begin{array}{c}\text { Sediment load } \\
\text { of event } \\
\text { kg }\end{array}$ & $\begin{array}{l}\text { Sediment load } \\
\text { of first } \\
\text { peak } \\
\text { kg }\end{array}$ & $\begin{array}{c}\text { Contribution } \\
\text { of first peak } \\
\text { to total load } \\
\%\end{array}$ \\
\hline 29 Apr 2006 & 88.6 & 19.0 & 3156 & 1083 & 94.6 & 5.6 & 6.0 \\
\hline 29 Oct 2006 & 92.2 & 15.5 & 570 & 317 & 20.3 & 0.5 & 2.3 \\
\hline 1 Jan 2007 & 360.8 & 11.5 & 712 & 166 & 143.2 & 0.1 & 0.1 \\
\hline 1 Mar 2007 & 583.7 & 13.3 & 729 & 373 & 215.1 & 1.8 & 0.8 \\
\hline 10 Jun 2007 & 255.2 & 15.9 & 26565 & 8243 & 2481.3 & 42.0 & 1.7 \\
\hline $28 \mathrm{Jul} 2012$ & 661.3 & 51.7 & 2340 & 499 & 145.9 & 1.1 & 0.8 \\
\hline Experiment 1 & 21.7 & 8.69 & $->$ & 890 & $->$ & 2.2 & - \\
\hline Experiment 2 & 21.6 & 7.94 & $->$ & 290 & $->$ & 1.6 & - \\
\hline
\end{tabular}

\section{Conclusions}

Two flooding experiments in a stream draining a small agricultural catchment clearly indicate resuspension of fine sediments from the stream bed. During the first experiment, suspended sediment load decreased from 16.2 to $2.2 \mathrm{~kg}$ along the stream according to the decrease of flow. During the second experiment, less sediment was resuspended and transported through the different sections of the stream (12.6 to $0.6 \mathrm{~kg}$ along the stream) due to the depletion of easily available sediments from the stream bed. The evaluation of flow and travel times indicates that the first peak of the sedigraphs of natural events in this stream is indeed caused by the resuspension of stream bed sediments. The sediment loads of the first peak of natural events may contribute between 0.1 and $6 \%$ of the total sediment load, depending on total flow volume.

Our future work will focus on the depletion of stream bed sediments during long-lasting events, including grain size analyses and hysteresis effects, to more fully understand the physical processes of in-stream sediment transport. Furthermore, it would be of interest to compare the results of this study with similar experiments for different hydrological conditions.

Acknowledgements. We would like acknowledge financial support from the Austrian Science Funds (FWF) as part of the Vienna Doctoral Programme on Water Resource Systems (DK-plus W1219-N22). We would also like to acknowledge funding of part of the equipment in the Hydrology Open Air Laboratory (HOAL) through the Innovative Projects Programme of the Vienna University of Technology. We are especially grateful to the fire brigades of Petzenkirchen and Scheibbs for the free loan of the pumps and Miriam Abietar, Franz Aigner, Thomas Bauer, Edith Brandstetter, Charles-Olivier Corbeil, Julia Derx, Ricarda Frenzl, Peter Haas, Rosemarie Hoesl, Silvia Jungwirth, Matthias Karner, Carmen Krammer, Hose Luis Salinas, Guenther Schmid, Margaret Stevenson, Rita Sturmlechner, Johannes Wagenhofer,
Stefan Wippl, Markus Wittek and Robert Wittek for assisting with the field experiments.

Edited by: M. Mikos

\section{References}

Blöschl, G. and Zehe, E.: On hydrological predictability. Hydrol. Process., 19, 3923-3929, 2005.

Brasington, J. and Richards, K.: Turbidity and suspended sediment dynamics in small catchments in the Nepal Middle Hills, Hydrol. Process., 14, 2559-2574, 2000.

Bryan, R. B. and Brun, S. E.: Laboratory experiments on sequential scour/deposition and their application to the development of banded vegetation, Catena, 37, 147-163, 1999.

DeRose, R. C., Prosser, I. P., Weisse, M., and Hughes, A. O.: Patterns of Erosion and Sediment and Nutrient Transport in the Murray-Darling Basin, CSIRO Land and Water Technical Report 32/03, CSIRO, Canberra, Australia, 2003.

Eder A., Strauss, P., Krueger, T., and Quinton, J. N.: Comparative Calculation of Suspended sediment loads with respect to hysteresis effects (in the Petzenkichen catchment, Austria), J. Hydrol., 389, 168-176, 2010.

FAO, ISRIC and ISSS: World Reference Base for Soil Resources. Food and Agriculture Organization of the United Nations, International Soil Reference and Information Centre, International Society of Soil Science, Rome, ISBN 92-5-104141-5, 1998.

Giménez, R. , Casalí, J., Grande, I., Díez, J., Campo, M. A., Álvarez-Mozos, J., and Goñi, M.: Factors controlling sediment export in a small agricultural watershed in Navarre (Spain), Agr. Water Manage., 110, 1-8, 2012.

Gooseff, M. N., Hall Jr., R. O., and Tank, J. L.: Relating transient storage to channel complexity in streams of varying land use in Jackson Hole, Wyoming, Water Resour. Res., 43, W01417, doi:10.1029/2005WR004626, 2007.

Kovacs, A., Honti, M., Eder, A., Zessner, M., Clement, A., and Blöschl, G.: Identification of phosphorus emission hotspots in agricultural catchments, Sci. Total Environ., 433, 74-88, 2012.

Kresser, W.: Gedanken zur Geschiebe- und Schwebstoffführung der Gewässer, Öster. Wasserwirt., 16, 6-11, 1964. 
Kronvang, B., Laubel, A., and Grant, R.: Suspended sediment and particulate phosphorus transport and delivery pathways in an arable catchment, Gelbaek stream, Denmark, Hydrol. Process., 11, 627-642, 1997.

Lana-Renault, N. and Regüés, D.: Seasonal patterns of suspended sediment transport in an abandoned farmland catchment in the Central Spanish Pyrenees, Earth Surf. Proc. Land., 34, 12911301, 2009.

Lenzi, M. A. and Marchi, L.: Suspended Sediment Load During Floods in a Small Stream of the Dolomites (Northeastern Italy), Catena, 39, 267-282, 2000.

Merritt, W. S., Letcher, R. A., and Jakeman, A. J.: A review of erosion and sediment transport models, Environ. Model. Softw., 18, 761-799, 2003.

Millington, A. C.: Relationship between three scales of erosion measurement on two small basins in Sierra Leone, in: Erosion and Sediment Transport Measurement, Proc. Florence Symposium, Florence, Italy, 485-492, 1981.

Mudroch, A. and Azcue, J.: Manual of Aquatic Sediment Sampling, CRC Press, Inc., Boca Raton, FL., ISBN 1-56670-029-9, 1995.

Parsons, A. J. and Stromberg, G. L.: Experimental analysis of size and distance of travel of unconstrained particles in interill flow, Water Resour. Res., 34, 2377-2381, 1998.

Petticrew, E. L., Krein, A., and Walling, D. E.: Evaluating fine sediment mobilization and storage in a gravel-bed river using controlled reservoir releases, Hydrol. Process., 21, 198-210, 2007.
Prosser, I. P., Rutherford, I. D., Olley, J. M., Young, W. J., Wallbrink, P. J., and Moran, C. J.: Large-scale patterns of erosion and sediment transport in river networks, with examples from Australia, Mar. Freshw. Res., 52, 81-99, 2001.

Quinton, J. A., Strauss, P., Miller, N., Azazoglu, E., Yli-Halla, M., and Uusitalo, R.: The potential for soil phosphorus tests to predict phosphorus losses in overland flow, J. Plant Nutrition and Soil Science, 166, 432-437, 2003.

Soler, M., Latron, J., and Gallart, F.: Relationships between suspended sediment concentrations and discharge in two small research basins in a mountainous Mediterranean area (Vallcebre, Eastern Pyrenees), Geomorphology, 98, 143-152, 2008.

Walling, D. E.: Erosion and sediment yield research - some recent perspectives, J. Hydrol., 100, 113-141, 1988.

Williams, G. P.: Sediment concentration versus water discharge during single hydrological events in rivers, J. Hydrol., 111, 89-106, 1989.

Wondzell, S. M., Gooseff, M. N., and McGlynn, B. L.: An analysis of alternative conceptual models relating hyporheic exchange flow to diel fluctuations in discharge during baseflow recession, Hydrol. Process., 24, 686-694, 2010.

Yeshaneh, E., Eder, A., and Blöschl, G.: Temporal variation of Suspended Sediment transport in the Koga Catchment, North Western Ethiopia and environmental implications, Hydrol. Process., doi:10.1002/hyp.10090, in press, 2013. 